os seek to provide more-realistic representations of socio-economics by simulating oे the economy through the interactions of of a large number of different agents, on the basis of specific rules. ABMs are widely $\checkmark$ used in finance, but have yet to be seriously applied to climate change. These are promising developments.

Now, a concerted effort is required by the research community to explore as many potential avenues as possible to better estimate the costs of action and inaction on climate change. The IPCC should distil what policymakers need to inform their decision-making. Learned societies and national academies must bring together researchers from a wide range of relevant disciplines to focus attention on improving economic modelling quickly.

Bangladeshi farmers and Cairo citydwellers are at severe risk of flooding and storms; southern Europe and parts of Africa and the Americas are threatened by desertification. Perhaps hundreds of millions of people may need to migrate as a result, posing an immense risk of conflict.

There is huge potential in future technologies that can drive change. These are omitted or badly underestimated in our current climate modelling - deeply damaging our guidance for policymaking. The well-being and prosperity of future generations are worth more.

Nicholas Stern is chair of the Grantham Research Institute on Climate Change and the Environment at the London School of Economics and Political Science (LSE), and president of the British Academy. e-mail:n.stern@lse.ac.uk

1. IPCC. Climate Change 2014: Impacts, Adaptation, and Vulnerability. Contribution of Working Group II to the Fifth Assessment Report of the Intergovernmental Panel on Climate Change (Cambridge Univ. Press, (2014).

2. Schaeffer, M. et al. Nature Clim. Change 2, 867-870 (2012).

3. IPCC. Climate Change 2014: Mitigation of Climate Change. Contribution of Working Group III to the Fifth Assessment Report of the Intergovernmental Panel on Climate Change (Cambridge Univ. Press, 2014).

4. Stern, N. Why are We Waiting?: The Logic, Urgency, and Promise of Tackling Climate Change (MIT Press, 2015).

5. Aghion, P. et al. Path Dependence, Innovation and the Economics of Climate Change (Grantham Research Inst., 2014).

6. Dechezleprêtre, A., Martin, R. \& Mohnen, M. Knowledge Spillovers from Clean and Dirty Technologies: A Patent Citation Analysis (Grantham Research Inst., 2013).

7. Dietz, S. \& Stern, N. Econ. J. 583, 574-620 (2015).

8. Gillingham, K. et al. National Bureau of Economic Research Working Paper No. 21637 (2015); available at http://dx.doi. org/10.3386/w21637

9. Farmer, J. D., Hepburn, C., Mealy, P. \& Teytelboym, A. Environ. Res. Econ. 62, 329-357 (2015).

10.Golosov, M. et al. Econometrica 82, 41-88 (2014).

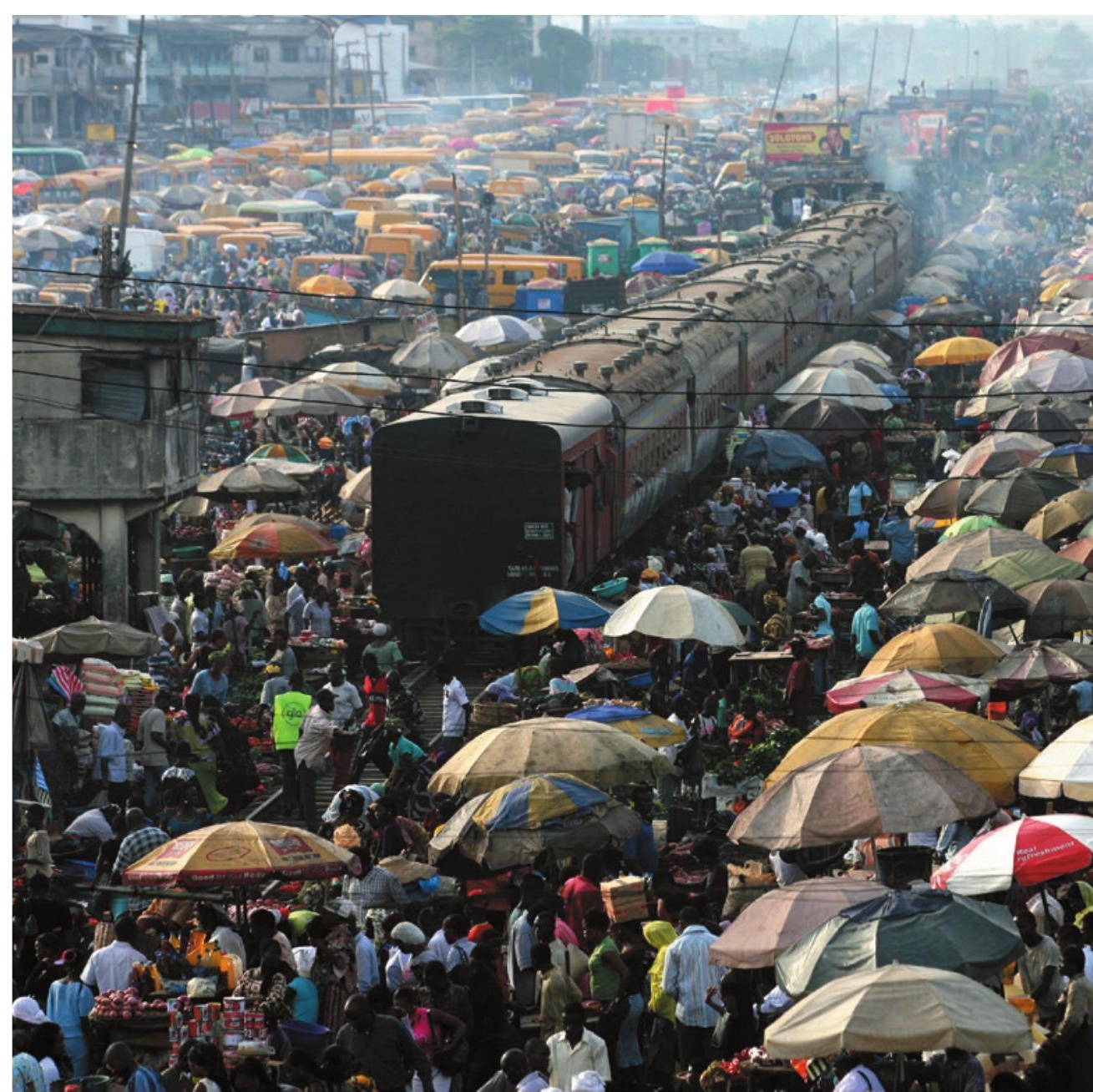

Oshodi market in Lagos.

\title{
Slow down
}

population growth

\author{
Within a decade, women everywhere should have \\ access to quality contraceptive services, \\ argues John Bongaarts.
}

I n 2100, our planet is expected to be home to 11.2 billion people. That's a more than $50 \%$ increase on today's 7.3 billion $^{1}$. This expansion of humanity is likely to be spread unevenly across the world. In the most developed regions, we expect declines (such as in Europe and east Asia) or little further growth (as in the Americas; see 'Bulges, gaps and shifts'). Substantial further growth

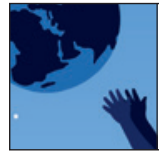

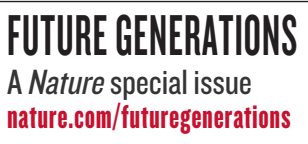

is anticipated in the least developed regions of south and west Asia (including in India and Pakistan) and north Africa (for example, in Egypt). By far the largest increase is projected in sub-Saharan Africa with a quadrupling of population - from just shy of 1 billion currently to 3.9 billion.

This potential addition of 4 billion people to the poorest regions of the globe is an obstacle to development that makes it difficult to be optimistic about their futures. Rapid population growth, with attendant consumption and waste, has pervasive adverse effects on societies 
$\checkmark$ and the world's ecosystems (see 'Four ways population rise takes its toll'). Many countries would be better off with lower population growth and birth rates. This is exemplified by the east Asian 'tiger' economies, including South Korea and Taiwan, that in recent decades have seen rapid increases in per capita incomes as birth rates declined. The boost to economic growth that follows a decline in fertility is referred to as the 'demographic dividend' ${ }^{2}$.

So, how can the population juggernaut be stopped, or at least slowed?

\section{WHAT CAN BE DONE}

Since the 1960s, the main policy response to rapid population growth, alongside investments to improve education and health, has been the implementation of voluntary family-planning programmes ${ }^{3}$. To make contraception accessible, these programmes train staff, subsidize costs and develop distribution schemes - for example, clinics, drug stores and other delivery systems. Equally important, they provide education about the health and the socio-economic benefits of using contraception and having smaller families. The key reason for these programmes is to address the substantial level of unwanted and unplanned pregnancy, as well as an unsatisfied demand for contraception. About 74 million unplanned pregnancies occur each year in the developing world (39\% of annual developing-world pregnancies). About half of these end in induced abortions ${ }^{4}$.

Among the reasons for unwanted and unplanned pregnancies are low levels of female education, a lack of knowledge about and access to contraception, insufficient supplies and services, cost and fear of side effects. Just as problematic are opposition from spouses and other family members and traditional gender roles that support a desire for large families. To reduce unintended pregnancies, family-planning programmes must go beyond simply providing supplies and services; they must also reduce or eliminate these other obstacles.

The most persuasive evidence that such programmes work comes from field experiments, such as the one that began in 1977 in the Matlab region of Bangladesh ${ }^{5}$. A control area of Matlab received the same limited family-planning

services as the rest "Inparticular, of the country. An education experimental area was of girls is a provided with free powerful services and supplies, brake on home visits by well- fertility." trained female familyplanning workers, and comprehensive media communication. Outreach to husbands, village leaders and religious leaders addressed potential social and familial objections.

The results were clear-cut. Contraceptive use jumped from $5 \%$ to $33 \%$ among married women of reproductive age in the experimental area. In the control area, little changed. As a result, fertility declined rapidly in the experimental area. A difference of about 1.5 births per woman between the experimental and control areas was observed until 1990, and a smaller difference continued beyond 1996, when the experiment ended. Among the long-term consequences of this difference were the children in the experimental area being educated to higher levels, families having greater household assets, and the greater use of preventive health services. The experiment demonstrated that familyplanning programmes can succeed even in highly traditional societies.

Contemporary evidence is fully consistent with the Matlab record. For example, countries that have suddenly implemented comprehensive family-planning programmes (such as Iran in 1989 and Rwanda in the mid-2000s) have seen rapid subsequent changes in reproductive behaviour.

Iran's fertility declined at an extraordinary pace from 5.6 births per woman in the late 1980 s to 2.6 a decade later ${ }^{6}$. In Rwanda, fertility dropped from 6.1 in 2005 to 4.6 in 2010 , and the proportion of married women using contraception jumped from $17 \%$ to $52 \%{ }^{7}$. Both countries' information programmes shifted norms by including messages about the benefits of smaller families, raising the demand for family-planning services.

Any acceleration of fertility decline changes the trajectory of future population growth. This impact can be large, as demonstrated by a comparison of alternative United Nations population projections ${ }^{1}$ for subSaharan Africa. With major investments in family planning, the fertility trajectory could easily be reduced by 0.5 births per woman within a few years after the start of the intervention. This would lead to a population of 2.8 billion in sub-Saharan Africa by 2100 (see 'Where will we be?'). That is around 1 billion fewer people than in the businessas-usual projection.

Family-planning programmes are most effective where socio-economic conditions

WIER M| ME RE? By 2100 , our planet is expected to be home to 11.2 billion

WEERE WLE WE? people - over $50 \%$ more than in 2015.

1 Projected population growth by region

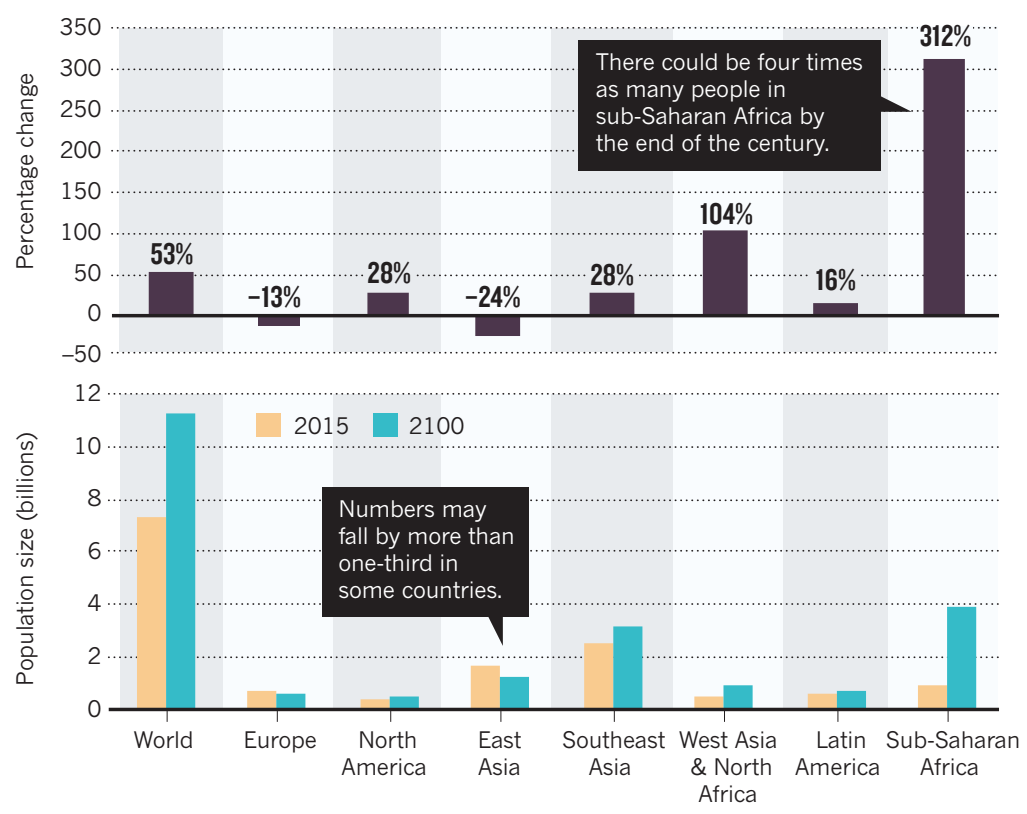

2 Three trajectories for population in sub-Saharan Africa

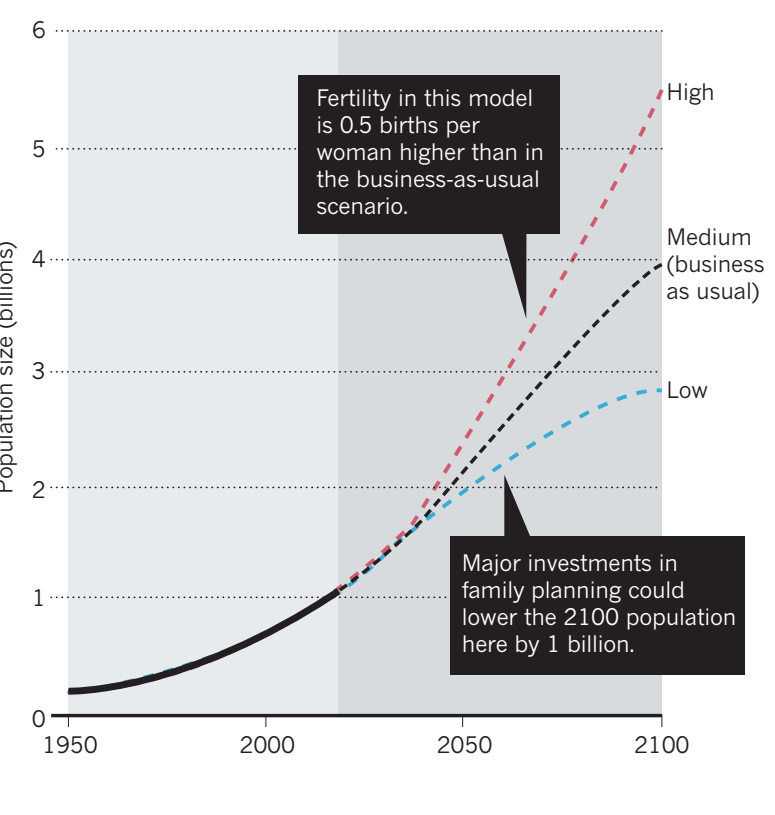


are improving. In particular, education of girls is a powerful brake on fertility. Educated women marry later, tend to want smaller families (in part, because the opportunity costs of childbearing are higher for these women) and are more capable of overcoming obstacles to their use of family planning. However, educated women must have access to contraception to act on their reproductive preferences. Family planning, education (of women and men) and socio-economic development are mutually reinforcing, and should be pursued together.

\section{EVOLUTION OF SUPPORT}

Family-planning programmes have been controversial, and support for them has fluctuated widely over the past half-century ${ }^{3}$. An initial surge of investment was made in the 1960s and early 1970s, as the UN and donor countries urged developing countries to address high fertility and rapid population growth. Several such countries accused the industrialized nations of making neo-colonial and imperialistic efforts to keep them weak and impoverished.

The Catholic Church, long opposed to artificial birth control and abortion, took an increasingly aggressive stance in opposition to government-sponsored family planning programmes worldwide. And when Republicans have occupied the White House, US lawmakers have also generally been unsupportive of international familyplanning programmes - reducing funding and adding onerous restrictions.

Nonetheless, contraceptive use rose steadily in Asia and Latin America during the 1980s (see go.nature.com/r2oqrl). Then, in the 1990s, aid for family planning was diverted to fight the AIDS epidemic in Africa and elsewhere. Moreover, the fertility declines in Asia and Latin America led to optimism that population growth in Africa would soon slow.

Political and religious opponents were able to draw support for their views from a disagreement stirring in the academic literature: some economists argued that voluntary family-planning programmes are ineffective ${ }^{8}$. Conventional economic theory considers parents as people who want to maximize utility, and, who - within their budget - choose the number of children that they have in the same way that they might choose how many televisions or bicycles to buy.

An obvious problem with this reasoning is that durable goods require an active purchase, whereas pregnancies occur unless an effort is made to avoid them. Furthermore, economic theories also typically assume that the cost (monetary, social and practical) of contraception is sufficiently low so as not to influence decision-making. From this academic perspective, the occurrence of unwanted pregnancies should be as rare

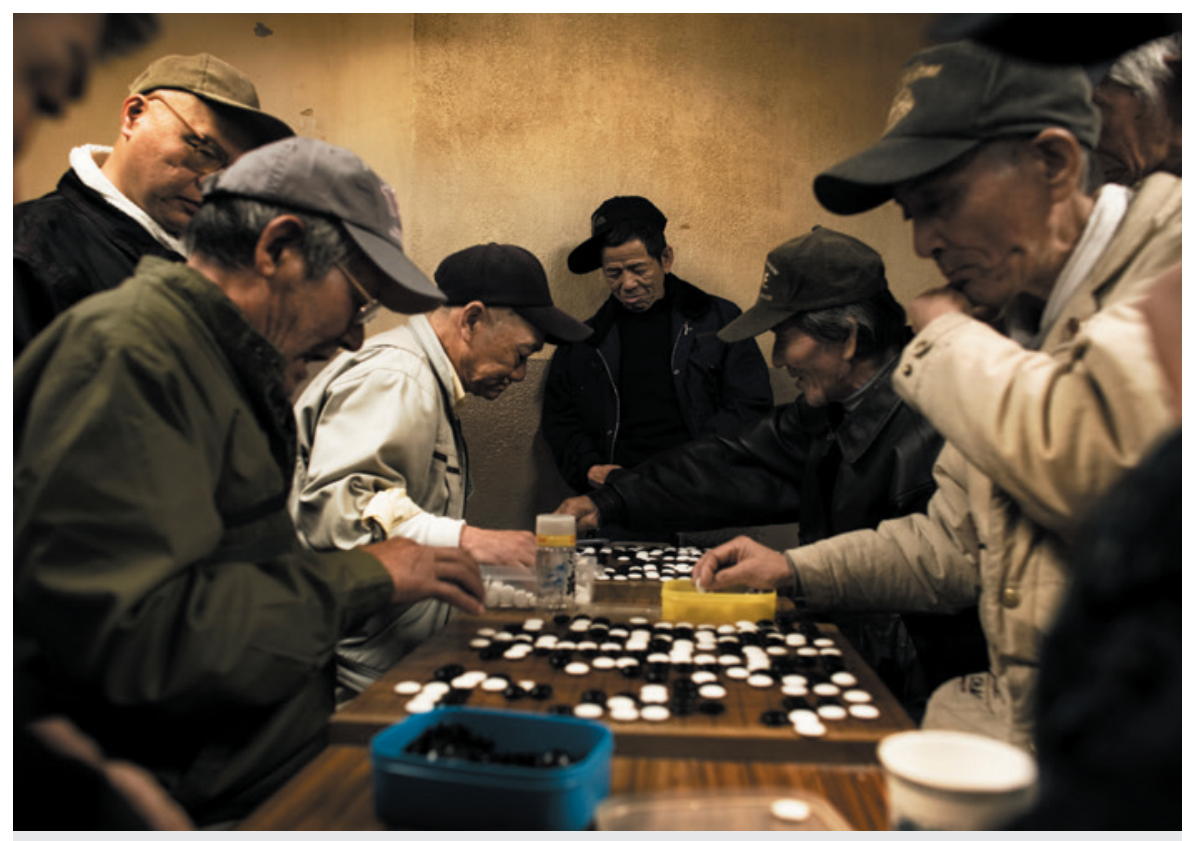

Over-65s make up more than one-quarter of Japan's population.

\section{DEMOGRAPHIC TRENDS Bulges, gaps and shifts}

Ageing. The median age of populations is rising, especially in the developed world, as a consequence of lower birth rates and rising lifespans. Europe and Japan now host the highest proportion of people aged over 65. Further increase in this proportion is expected, putting enormous pressure on pension and health-care systems, and slowing economic growth.

Migration. The flow of people from poor and war-torn countries and continents to nearby developed ones (for example, from Africa and the Middle East to Europe) is rising. The tension this creates will grow as populations in poor countries rise, and while the economic disparities between sending and receiving countries remain large.

Low birth rate. In most developed countries and in a growing number of Asian and Latin American nations, women are having fewer than two children each - the level needed for long-term population stability. This causes population ageing and decline

as people having unwanted new televisions; thus family-planning schemes should not be given priority.

Needless to say, that is not how things work in the real world. Avoiding unintended pregnancies is difficult even for women who use relatively effective methods and as a result, tens of millions of such pregnancies occur each year. Happily, the accumulating evidence of plummeting birth rates in a few (for example, the populations of Eastern Europe and Japan will probably shrink by more than one-third by 2100 ). The nearabsence of children to provide support will make life difficult for the elderly in countries where societal safety nets are weak (such as China).

Missing women. There are 100 million fewer women than naturally expected owing to sex-selective abortion and greater female mortality throughout life (for example, from female infanticide). In the past two decades, the number of such abortions has risen to about 1.5 million per year as a result of increased availability of low-cost ultrasound and genetic screening (to determine fetus sex), and greater access to methods for terminating pregnancies in countries that have strong cultural preferences for boys. These statistics document the widespread gender discrimination that still exists in many countries. An excess of single men may lead to social unrest and trafficking in women and girls.

countries (such as Ethiopia and Rwanda) has now largely persuaded policymakers of the cost-effectiveness of these programmes ${ }^{9}$. Religious and political opposition persists.

\section{WHAT NOW?}

To reduce rapid population growth and high birth rates, it is essential to start with a clear objective: within a decade, women everywhere should have access to quality 


\section{GROWING PAINS}

\section{Four ways population rise takes its toll}

\begin{abstract}
Environmental degradation. Unprecedented global threats such as climate change and decreasing biodiversity have been building and will become more severe as populations, economies and consumption grow. Crucial local environmental problems - including shortages of fresh water and arable land, mounting waste, and air, water and soil pollution - adversely affect health and threaten the expansion of food production required to feed more people a better diet.
\end{abstract}

Economic stagnation. In poor societies, populations often double in size in two or three decades. Industries, offices, housing, schools, health clinics and infrastructure must be built at least at the same rate. Many communities are unable to keep up - as is evident from high unemployment rates, explosive growth of slum populations, overcrowded schools and health facilities and dilapidated public infrastructure (such as roads, sewage systems and power grids). Furthermore, in rapidly growing regions, about half ${ }^{1}$ of the

population is aged under 20 . The low ratio of workers to dependents depresses living standards and makes it more difficult to invest in the physical and human capital needed. The size of the formal labour force is also limited when women remain at home to care for large families.

Maternal mortality. High birth rates mean frequent childbearing. Each pregnancy is associated with a risk of death or disability, and this is highest in countries with weak health-care systems. For example, in the poorest countries of West Africa, a woman's risk of dying in childbirth before the end of her reproductive years is about 1 in 20.

Political unrest. Youth unemployment becomes widespread when economies are unable to provide jobs. Vigorous competition for few jobs leads to low wages, which in turn contribute to poverty. Large numbers of unemployed and frustrated young men, in particular, fuel socioeconomic tensions, high crime rates and political instability.

on Family Planning, at which many donors and governments renewed or increased their commitments.

Still, only $1 \%$ of all overseas development assistance (ODA) is now allocated to family planning ${ }^{10}$. This amount is inadequate; in too many countries, programmes remain weak and politi-

cal commitment is lacking.

The proportion of ODA allocated

"Importantly, coercion of any traceptive use, such as incorrect rumours about side effects and conservative social attitudes, should be addressed by the education of women and men, media campaigns and collaboration with community leaders.

These efforts can be led by governments but better results are obtained when services are distributed through multiple channels, including private commercial providers and non-governmental organizations. Importantly, coercion of any kind should be ruled out. Women and men have the right to decide freely on the number, timing and spacing of children, and on the means to achieve their reproductive goals.

Achieving these aims requires substantially more resources than are available now. Funds are needed to build and equip clinics, to train and pay providers and to subsidize the direct cost of methods and services that are out of the reach of too many poor people. Over the past decade, investments in the developing world have risen, especially after the 2012 London Summit to family planning

should be raised to $2 \%$ and developingcountries governments should expand their funding by an equivalent proportion. Such a doubling of funding will be more than repaid by savings in other sectors such as education and health care in future years.

\section{FROM THE TOP}

The final, crucial ingredient for success is political will and a commitment to family planning at the highest levels of national and international policymaking. A fundamental reason for the low priority assigned to the issue is that it is considered a health and human-rights problem.

Hence, family planning is part of the health budgets of donors and the responsibility for family-planning programmes is assigned to ministers of health throughout the developing world. Most poor countries are battling a range of diseases, and family planning is often not seen as a high health priority. From a broader development perspective, the low priority is nonsensical.

Several actions would remedy this situation. At the international level, development agencies and donors should hire more population experts (the World Bank, for example, employs thousands of economists but only a few demographers). These organizations write hundreds of reports on every dimension of development, yet only a fraction comment on population trends. Such reports should include a discussion of the role of demographic shifts in relevant sectors, of the development benefits of reduced birth rates and of the options available to change these trends.

At the national level, similar changes are needed. Typically, population trends are noted in government plans but are considered immutable and therefore of little interest. Ministries of finance or planning commissions often make detailed projections for specific sectors but rarely examine alternative population trajectories. They should. Economists at the Copenhagen Consensus Center, a think tank, last year ranked family planning as one of the most cost-effective development interventions (see go.nature.com/fumoop).

Family planning must be reclassified as a development intervention (as well as being a health and human-rights intervention) to give it the high national and global priority it deserves. This would lead to a more cost-effective use of scarce development resources, and to more rapid growth in living standards in poor countries.

John Bongaarts is vice-president and distinguished scholar at the Population Council, New York City, New York, USA. e-mail:jbongaarts@popcouncil.org

1. United Nations Department of Economic and Social Affairs. World Population Prospects: The 2015 Revision (United Nations, 2015).

2. Bloom, D. E., Canning, D. \& Sevilla, J. The Demographic Dividend (RAND Corporation, 2003).

3. May, J. F. World Population Policies: Their Origin Evolution, and Impact (Springer, 2012).

4. Singh, S., Darroch, J. E. \& Ashford, L. S. Adding It Up: The Costs and Benefits of Investing in Sexual and Reproductive Health (Guttmacher Institute, 2014).

5. Cleland, J., Phillips, J. F., Amin, S. \& Kamal, G. M. The Determinants of Reproductive Change in Bangladesh: Success in a Challenging Environment (World Bank, 1994).

6. Abbasi-Shavazia, M. J. \& McDonald, P. Asian Pop. Stud. 2, 217-237 (2006).

7. Westoff, C. F., Popul. Dev. Rev. 38 (suppl. 1), 169-178 (2013).

8. Pritchett, L. Popul. Dev. Rev. 20, 1-55 (1994).

9. Bongaarts, J., Cleland, J., Townsend, J., Bertrand, J. \& Das Gupta, M. Family Planning Programs for the 21st Century: Rationale and Design (Population Council, 2012).

10.Wexler, A. \& Kates, J. Donor Government Assistance for Family Planning in 2014 (Kaiser Family Foundation, 2015). 